\title{
Forest Fire and Trespassing Detection using WSN with PIR sensor
}

\author{
W. Sylvia Lilly Jebarani, M. Venkatesh, M. V. K. GrishKanna
}

\begin{abstract}
Fire occurring in forest has become a major crises, the hard part of this is passing information about fire occurred is delay which in turn allow to increase the spread of fire. There are two preeminent reasons on delay, first is place or region in which fire has occurred and the other is passing information about fire to outer world. Forest fire can be controlled using appropriate technique and officials can control the wild fire before spreading, if the information is passed fast. Human trespassing is one of the dominant acumen for wild fires. In order to know the type of the fire depending upon the region and also deportation of data about fire occurred, we framed a lay out, forest fire detector that uses wireless sensor networks. The detector is able to inform us whether it is a crown fire or ground fire depending upon the region using fire sensors and PIR via NodeMCU ESP8266. PIR is used to detect the presence of humans within the preserved regions of wild. The detectors that are connected to the NodeMCU pass the information to tan other NodeMCU using server client configuration. Depending on the type of fire, sprinklers are activated to control ground fire and drones carrying fire resistant dry chemicals are used to spread them from above for crown fire.

Keywords:-fire detection, NodeMCU, PIR, flame sensor, WSN, client server configuration.
\end{abstract}

\section{INTRODUCTION}

Forests are important in the ecosystem on earth. They are inseparable even for our day to day life, namely as a producer of oxygen to mankind and bears the predicate as the lungs of the world. The problem here is that when a forest experiences a fire, there will be a lot of harm to both the humans, animals and also to the ecosystem surrounding it. This leads to abrupt changes in climate of the ecosystem, ranging from air pollution to the destruction of the ecosystem in the forest itself. There will be a lot of death in the animal kind and the remaining living animals also lose their habitat.In general there are various reasons for a forest fire to occur which is classified into natural and manmade fire, and depending upon the region of fire in the tree the methods that are used to control them varies. The major reason for forest fires is lightning but this is not the only reason. It is also caused due to human negligence which results in a major disaster. Fire is known for its fast ways of spreading from shrub to shrub known as crawling and another type is spreading over the crown region of the trees cutting of the oxygen supply.

Revised Manuscript Received on May 15, 2020.

* Correspondence Author

Dr. W. Sylvia Lilly Jebarani*, Associate Professor, Department of Electronics and Communication Engineering, MEPCO Schlenk Engineering College, Sivakasi, India. E-mail: wsylvia@mepcoeng.ac.in

M. Venkatesh, Scholar, Department of Electronic and Communication, MEPCO Schlenk Engineering College, Sivakasi, India. E-mail: venkatvav98@gmail.com

M. V. K. Grishkanna, Scholar, Department of Electronics and Communication, MEPCO Schlenk Engineering College, Sivakasi, India. Email: grishromex@gmail.com

(c) The Authors. Published by Blue Eyes Intelligence Engineering and Sciences Publication (BEIESP). This is an open access article under the CC BY-NC-ND license (http://creativecommons.org/licenses/by-nc-nd/4.0/)
The dry leaves, branches of trees catch fire easily in the dry regions. The fire that occurs in the branches are spread via wind to a larger region of landscape in no time. The problem here is the time taken by the authorities in handling the forest fire. One of the reasons is the lack of information about the forest fire and the other does not know the type of fire that has occurred. Hence, we conduct a study that aims to detect the type of fires and inform the authorities in the event of fire.

According to the tabulated data from Lok Sabha the region destroyed by the forest fires of 2016 is 20,500 hectares which is more compared to the previous data of the year 2015 that is 15,900 hectares. Our ministry is implementing scheme "Forest Fire Control Methods" through which financial assistance are provided for the state governments. This scheme prevents human caused fire through proper detection are identified and rescued.

Early detection is the primary way for reducing the effects of wild fire. There are many ways of monitoring wild fires. Among these, satellite based detection is more popular but it has a drawbacks namely, taking long time for scanning and low resolution which limit the efficiency. for scanning and low resolution which limit the efficiency.

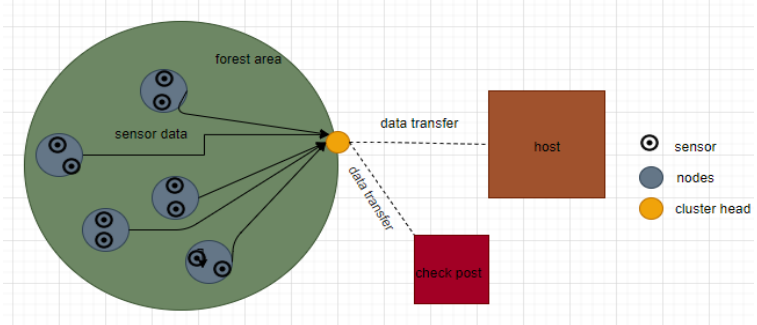

Fig. 1, Scenario for overall system

Thus in this proposed system, the sensor nodes are spread throughout the forest. They collect the data and pass them to the cluster heads. These proceed the information to the host creating a network as shown in the Fig. 1 .

\section{SYSTEM ARCHITECTURE}

\section{A. Wireless Sensor Networks}

A wireless sensor network (WSN) is a communication network made up of various sensor nodes that can be arranged in a star topology. They have the ability to selforganize and configure[1]. Here all the nodes are connected to a single cluster head which connects to the upper level of the network. This is illustrated in the Fig.1.

Published By:

Blue Eyes Intelligence Engineering

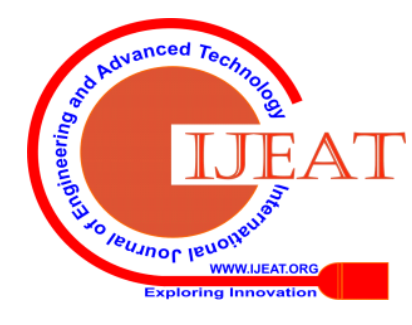




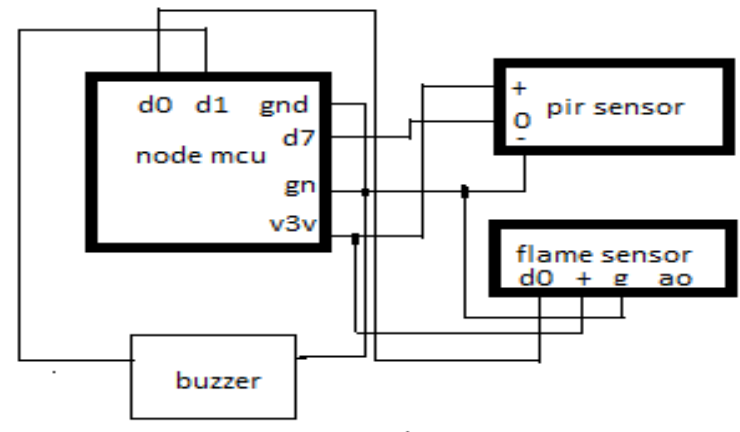

Fig.2. The Node using ESP8266

\section{B. Sensor Node and Gateway}

In this research we use a NodeMCU esp8266 for the nodes along with the sensors. It is basically attached to flame sensor and PIR sensor. But the nodes vary based on the position they are placed in a tree. Flame sensor detects the flame at the time of the fire. PIR sensor detects the presence of human during the time of fire leading to identify whether the fire is due to natural or manmade cause.

Therefore we use nodeMCU the low-cost Gateway. Fig.2 illustrates the nodal region of each cluster head interfaced with the sensors.

\section{SYSTEM DESIGN}

\section{A. General System Design}

This section explains about the design of the system which is used in the forest area, where basically no internet connection is available. This situation makes it difficult to transfer the information during the time of the wild fire. Thus we need a specialized design to transfer data from the forest to the outside world, thus we use wireless sensor networks[2]. As shown in Fig. 3, the communication is from the sensor nodes to the cluster head, from the cluster head send the sensor data to the client which is monitored.

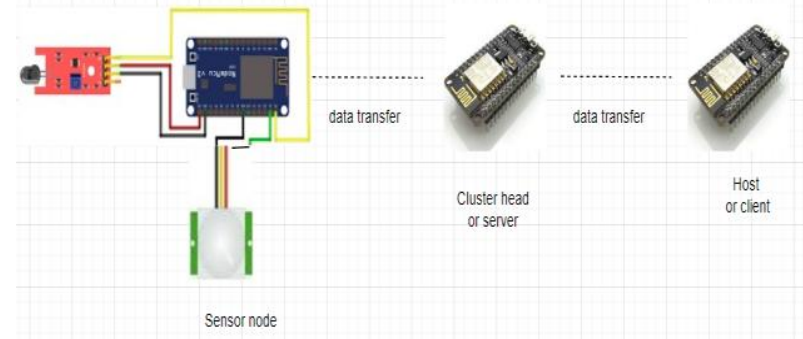

Fig. 3, Architecture of Client-Server Communication

\section{B. System Scenario}

In our experiment, we place 2 sensor nodes in the top and bottom of a tree forming a single node. Thus, in this way three nodes are formed using six sensor nodes. As shown in Fig. 1, these nodes pass the information to their cluster head at the time of fire. These are arranged in two parts. The first part of the system lies within the forest, another region lies on the outer environment. The cluster head forwards data from the nodes to the client. E.g. if a node detects a fire, it cannot send the data directly to the client because of very long distance.

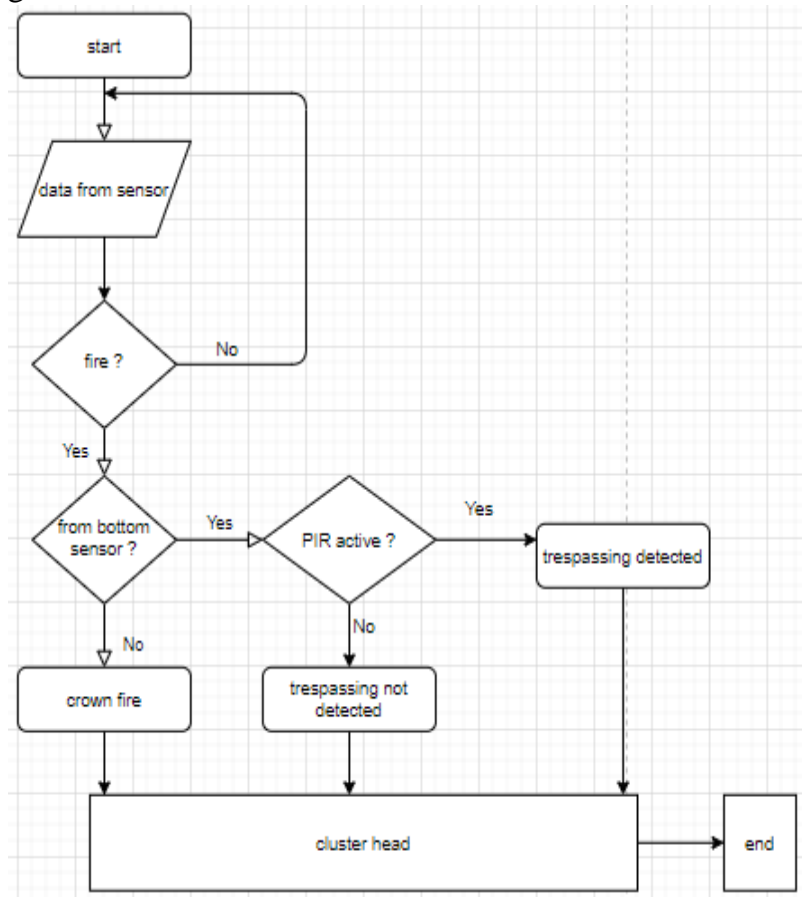

Fig. 4, Flowchart of Data Transfer from Sensor Node

Instead, the node forwards the data to the cluster head. This forwards the data to the Host using the client server architecture. From the sensor node detection of fire is made by the flame sensors and the movement of humans is detected by the PIR.

The sensor nodes which are located on the crown region of the tree are used to sense the crown fire. The sensor nodes that are present in the base of tree senses both the ground fire and the movement of trespassers. The location of the sensors can be used to locate the forest fire. Fig. 4, shows a flowchart of forest fire detection and data transmission to the cluster head while Fig. 5, shows flowchart of forwarding cluster head data to the client and activation of respective fire control methods.

\section{EXPERIMENT AND RESULT}

We conduct experiments in order to collect performance data. In this experiment we have 3 sensor nodes for crown fire and 3 sensor nodes for ground fire detection respectively. As the forest has tight trees, it can weaken the signal from the nodes[3]. As crown fire can only be produced by natural means there is no need for paying attention for trespassing at the top region of the forest while the ground fire is caused by both natural and manmade ways. Thus, human monitoring is needed in the surface region of the forest.

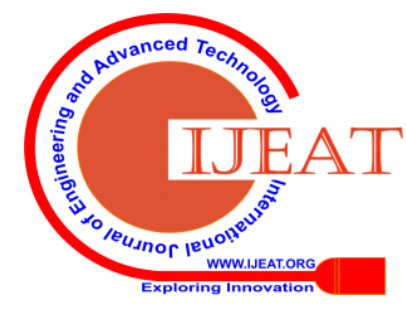




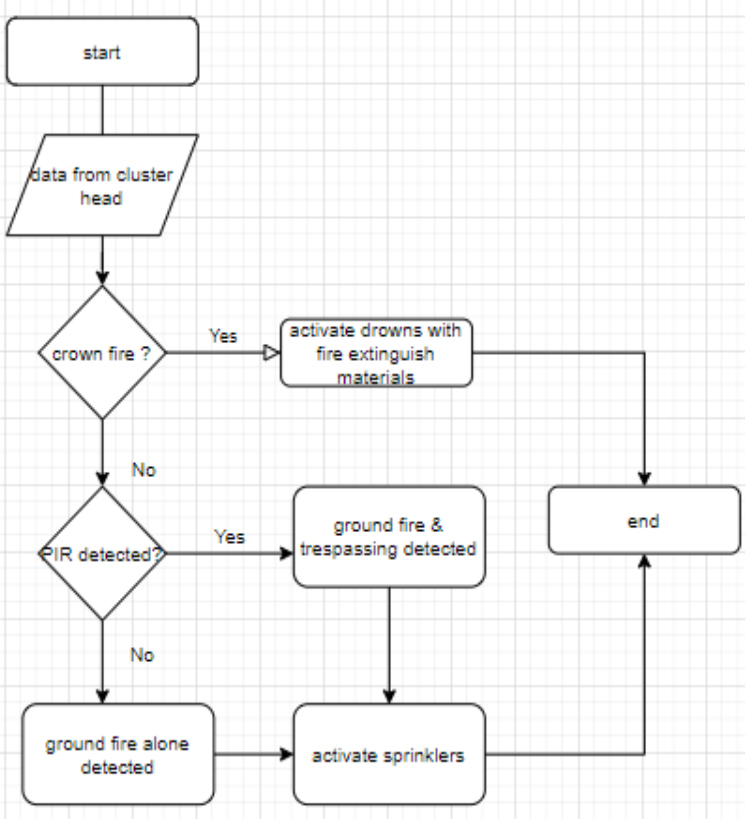

Fig. 5, Flowchart of Data Forwarding to the Host

When fire is detected on any of the flame sensors that are fitted in both top and bottom of a tree the sensor value becomes low, which usually remains high during idle time. The PIR value becomes high when it detects the motion of humans. This signal from the sensor which is digital is forwarded to the NodeMCU to which it is connected[4]. This digital data from the nodes are forwarded to the respective cluster heads. This data which is differentiated as crown or ground fire is transmitted to the Host that is located outside the region for forest. The data that the Host receives shows the type of fire that has occurred. This output shows all kind of possible outcomes, that is whether flame alone is detected or else whether it is detected along with motion for both ground and crown fire respectively.

Determination of the Number of Nodes to Cover Forest Areas

In determining the total number of nodes that has to be installed to cover the total forest area, the signal range of NodeMCU while sending / receiving a data must be considered. Another thing to note is by knowing the distance between the nodes helps in knowing whether data is transmitted or not. The location of a fire during a forest fire incident is a highly precious information. By getting the location on a real time basis, the fire fighters can reach the location quickly and start their service.

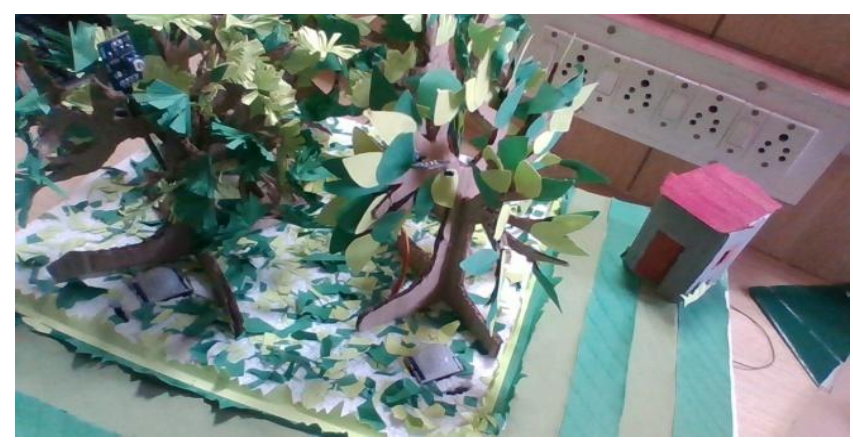

Forest Fire Detector Model

\section{RESULTS ANALYSIS}

With the help of the clusters present in the project occurrence of fire is found whether the fire is top end or bottom end. Once the ends are found sprinklers to reduce bottom end fire and drones to reduce top ends are applied as next step after fire occurred is controlled. As analysis we found that using this technique time and spreading of fire due to delay are reduced.

\section{CONCLUSION}

Forest fires utmost critical issues in multiple countries, which is even worse at the present state of global warning in the world. Thus prevention of wild fires or the advancements made in the ways they can be prevented or controlled are being concentrated by many nations worldwide in the recent times. The wireless sensor network has high benefits and the network can be simply placed on the place of interest or area of high risk. This project includes both sensor nodes as well as cluster nodes, which pass the information to the Host via client server architecture. For efficient detection of wild fire the sensor nodes should be small, energy efficient and not much expensive. They should be robust enough to function in the harsh environment of the forest. In our experiment in detecting the forest fire, we have also included some preliminary steps to control the fire till the forces come equipped.

We have set sprinklers to be activated at the time of ground fire detection. These sprinklers are basically electrical one so due to this manually work is reduced and fully automated. The sprinklers get triggered by the output from the flame sensor at the time of fire. These help in controlling the fire till the forest fire fighters come. At the same time the crown fire is controlled with the aid of firefighting drones. These drones are specially designed drones containing fire extinguishing chemicals which can control the spreading of fire. There are also drones that spray water with high pressure.

\section{REFERENCES}

1. Wateen A.Aliady; Saad A.Al-Ahmadi,"Energy Preserving Secure Measure Against Wormhole Attack in Wireless Sensor Networks", IEEE access., vol.7, pp. 2169-3936, Jun.2019.

2. Pradeep Kumar Singh; Amit Sharma, "An Insight to forest fire detection techniques using WSN ", 4th International Conference on Signal Processing, Computing and Control (ISPCC), IEEE conf., Sept. 2017.

3. Moumita Ghosh; Rama Sushil; Kaushik Ghosh, "Detecting and reporting forest fire through deployment of three dimensional multi sink wireless sensor network", 4th International Conference on Internet of Things: Smart Innovation and Usages (IoT-SIU),IEEE conf., April 2019

4. Kuan-Chung Lai; Bing-Huan ku; Chih-Yu Wen, "Using cooperative PIR sensing for human indoor localization", 2018 27th Wireless and Optical Communication Conference (WOCC).,IEEE conf., pp. 2379 1276., May 2018.

5. Y. Zhu, L. Xie, and T. Yuan, "Monitoring System for Forest Fire Based on Wireless Sensor Network," pp. 4245-4248, 2012.

6. D. V. Kirubaharan, A. J. C. Sunder, S. M. Ramesh, and P. Dhinakar, "Intruder Detection and Forest Fire Alert System with Using Wireless Sensor Network," vol. 1, no. 3, pp. 136-140, 2014.

Blue Eyes Intelligence Engineering 
7. R. Q. V. P. Chandrasekharan, "Forest Fire Detection Using Temperature Sensors Powered by Tree and Auto alarming Using Gsm,” Ijrsi 2(3) 23-28, vol. II, no. 100817, pp. 23-28, 2015

8. . L. R. Patil, D. Chopda, and M. Borse, "Forest-Fires Monitoring System Using Wireless Technology," vol. 6, no. 4, pp. 4-7, 2016.

9. W. San-urnl, P. Lekbunyasinl, M. Kodyool, and W. Wongsuwanl, "A Long-Range Low-Power Wireless Sensor Network Based on U-LoRa Technology for Tactical Troops Tracking Systems," pp. 5-8, 2017.

\section{AUTHORS PROFILE}

Dr. W. Sylvia Lilly Jebarani, ME., PHD, Associate Professor (Sr.Grade) Department Of Electronics and Communication Engineering. Mepco Schlenk Engineering College.

Sivakasi,India.wsylvia@mepcoeng.ac.in

M. Venkatesh,BE ECE Scholar Department Of Electronic And Communication. Mepco Schlenk Engineering College. Sivakasi,India. venkatvav98@gmail.com

M. V. K. Grishkanna, BE ECE Scholar Department Of Electronics And Communication Mepco Schlenk Engineering College. Sivakasi,India. grishromex@gmail.com

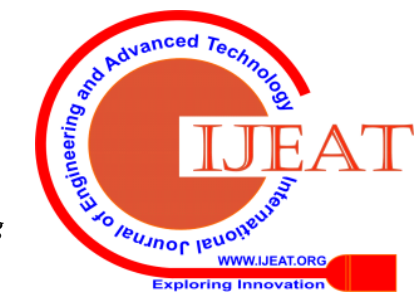

